EXTRACTION AND OPTIMATION OF RED GEDI LEAF (Abelmoschus manihot (L.) Medik.) ANTHOCYANIN USING THE UV-VIS SPECTROPHOTOMETRIC METHOD

\title{
EKSTRAKSI DAN OPTIMASI ANTOSIANIN DAUN GEDI MERAH (Abelmoschus manihot (L.) Medik.) DENGAN METODE SPEKTROFOTOMETRI UV-VIS
}

\author{
Makbul Renaldi Sahi ${ }^{1 *}$, Fatimawali $^{1)}$, Jainer Pasca Siampa ${ }^{1)}$ \\ ${ }^{1)}$ Program Studi Farmasi FMIPA UNSRAT Manado, 95115 \\ *makbulsahi@gmail.com
}

\begin{abstract}
Abelmoschus manihot (L.) Medik. (A. manihot) is a medicinal plant that contains forms of flavones, flavonols, isoflavones, anthocyanins and proanthocyanidins. This research was conducted to determine the optimum concentration, $\mathrm{pH}$ and temperature variables for anthocyanins in A. manihot leaves. The sample was extracted by using 1:10 methanol solvent maceration method using two methanol solvent systems with different acidifiers, namely $\mathrm{HCl}$ and Citric Acid. The results obtained on the optimization of concentration, pH and temperature on anthocyanin compounds showed mixed results with stable absorbance values in the range $0.2-0.8$ for certain variables.
\end{abstract}

Keywords: anthocyanin, Abelmoschus manihot (L.) Medik., UV-Vis Spectrophotometry

\begin{abstract}
ABSTRAK
Abelmoschus manihot (L.) Medik. (A. manihot) adalah tanaman obat yang mengandung flavon, flavonol, isoflavon, antosianin dan proantosianidin. Penelitian ini dilakukan untuk mengetahui variable konsentrasi, pH dan suhu optimum terhadap antosianin pada daun A. manihot. Sampel diekstraksi dengan metode maserasi pelarut metanol 1:10 menggunakan dua sistem pelarut Metanol dengan pengasam berbeda yaitu $\mathrm{HCl}$ dan Asam Sitrat. Hasil yang didapat pada optimasi konsentrasi, $\mathrm{pH}$ dan suhu pada senyawa antosianin menunjukkan hasil yang beragam dengan nilai absorbansi yang stabil pada kisaran $0,2-0,8$ pada variabel tertentu.
\end{abstract}

Kata kunci: antosianin, Abelmoschus manihot (L.) Medik., Spektrofotometri UV-Vis 


\section{PENDAHULUAN}

Flavonoid merupakan kelompok senyawa fenolik terbesar di alam yang biasanya ada di akar, batang, daun, kelopak, biji dan lain-lain. Lebih dari 2000 flavonoid yang berasal dari tumbuh-tumbuhan telah diidentifikasi, diantaranya senyawa antosianin, flavonol, dan flavon. Antosianin (dari bahasa Yunani anthos = bunga, kyanos, biru tua) adalah pigmen berwarna yang umumnya terdapat di bunga berwarna merah, ungu, dan biru. Pigmen ini juga terdapat di berbagai bagian tumbuhan lain, misalnya buah tertentu, batang, daun dan bahkan akar (Julianto, 2019).

Tumbuhan Gedi Merah merupakan tumbuhan tahunan tropis, famili Malvaceae yang banyak dijumpai di Sulawesi Utara. Tanaman gedi banyak ditemukan didaerah sekitar Desa Likupang Dua, yang merupakan daerah pesisir pantai yang terletak di Kecamatan Likupang Timur, Kabupaten Minahasa Utara. Tumbuhan Gedi biasa ditemukan di pekarangan rumah warga sedangkan khusus untuk tanaman gedi merah kebanyakan tumbuh diperkebunan dan daerah hutan sekitar desa.

Tumbuhan gedi biasa dijadikan sebagai bahan pangan sehari-hari, juga dimanfaatkan sebagai obat tradisional. Tumbuhan Gedi Merah mengandung quercetin-3-o- robinobiosid, hyperin, isoquercetin, gossipetin-8-oglukuronoid, myricetin, antosianin dan hyperoside (Banne et al., 2019).

Keberadaan antosianin di alam dan penyebarannya pada berbagai jenis tanaman, membuat antosianin memiliki karakter yang berbeda-beda. Hal ini menjadikan antosianin sebagai zat kimia organik, yang amat potensial dalam mengerahkan fungsi fisiologis pada berbagai organisme hidup, baik untuk manusia, hewan, serta pada tanaman itu sendiri. Dalam bidang pangan, antosianin digunakan sebagai bahan tambahan pangan yang dipakai sebagai pewarna makanan dan minuman alami, seperti warna antosianin dari jenis buah-buahan dan bunga yang dibuat dalam bentuk bubuk kering atau konsentrasi pekat yang selanjutnya ditambahkan ke dalam proses pembuatan makanan dan minuman (Priska et al., 2018).

Antosianin memiliki persentasi derajat degradasi yang tinggi, hal ini disebabkan karena antosianin memiliki sensivitas tinggi terhadap berbagai macam faktor, yakni suhu, perubahan $\mathrm{pH}$, ketersediaan oksigen, dan cahaya (Yusuf et al., 2018).
Antosianin lebih mudah larut dalam keadaan asam. Pada $\mathrm{pH}$ yang lebih rendah dari 2, antosianin berada sebagai kation (ion flavilium). Oleh karena itu, antosianin paling aman jika dikerjakan dalam larutan yang sedikit asam. Keadaan yang semakin asam mendekati $\mathrm{pH} 1$ akan menyebabkan semakin banyaknya pigmen antosianin berada dalam bentuk kation flavilium atau oksonium yang berwarna sehingga dengan mudah dapat terbaca pada spektrum absrobansi.

Berdasarkan hal diatas, peneliti ingin mengetahui bagaimana pengaruh penggunaan dua pengasam berbeda, dalam mengekstrak antosianin serta bagaimana optimasi konsentrasi, $\mathrm{pH}$ dan suhu terhadap kestabilan antosianin dalam daun gedi merah.

\section{METODOLOGI PENELITIAN Waktu dan Tempat Penelitian}

Penelitian ini dilaksanakan pada bulan Agustus 2019 sampai Februari 2020 di Laboratorium Kimia Farmasi, Program studi Farmasi Fakultas Matematika dan Ilmu Pengetahuan Alam, Universitas Sam Ratulangi Manado.

\section{Alat dan Bahan \\ Alat-alat}

Alat-alat yang digunakan dalam penelitian ini ialah spektrofotometer UV-Vis (Shimadzu 00780), ayakan, komputer pengolah data, kertas lakmus, pH meter digital (ATC), vortex mixer, timbangan analitik (aeADAM), pipet tetes, hot plate dan alat-alat gelas.

\section{Bahan}

Bahan-bahan yang dipakai ialah simplisia kering daun Gedi Merah, akuades, metanol, HCL $0.1 \%$, asam sitrat $3 \%, \mathrm{HCl}$ pekat, potasium klorida dan sodium asetat.

\section{Prosedur Kerja \\ Pengambilan Sampel}

Daun gedi merah diperoleh dari Desa Likupang 2, Kecamatan Likupang Timur, Kabupaten Minahasa Utara. Sampel yang digunakan adalah bagian daun tanaman gedi merah. Pengambilan sampel dengan cara memetik daun gedi mulai dari bagian tangkai hingga daun sampel.

\section{Pengolahan Sampel}

Pengolahan sampel meliputi pengeringan sampel dengan cara diangin-anginkan, tidak 
terkena paparan sinar matahari langsung. Pengeringan dilakukan untuk menghilangkan kadar air dalam bahan untuk memperlancar proses analisis dan menambah daya awet bahan tersebut yang selanjutnya dilakukan proses ekstraksi.

\section{Ekstraksi Sampel}

Sampel yang telah diolah dan dihaluskan dimaserasi dengan dua sistem pelarut metanol dalam kondisi asam dengan perbandingan 1;10 (100 gram serbuk : $1000 \mathrm{~mL}$ pelarut). Kedua pengasam yang dipakai adalah $0,1 \% \mathrm{HCl}$, dan $3 \%$ asam sitrat. Pengasaman dilakukan dengan mencampurkan pengasam sedikit demi sedikit dengan larutan pada masing-masing wadah, sambil dilihat $\mathrm{pH}$ larutan menggunakan kertas lakmus sampai menunjukkan indikator asam.

Maserasi dilakukan dalam wadah toples kaca, selama 24 jam pada suhu ruang. Ekstrak tersebut kemudian dimasukkan ke dalam oven untuk penguapan agar mendapatkan ekstrak kental. Untuk keperluan analisis, ekstrak kental tersebut disimpan dalam wadah toples kecil tertutup pada lemari es.

\section{Pembuatan larutan pH 1,0 dan pH 4,5}

Pembuatan larutan $\mathrm{pH}$ 1,0 dan 4,5 akan dipakai pada proses pengaturan $\mathrm{pH}$ pada ekstrak untuk melihat pengaruh $\mathrm{pH}$ terhadap antosianin dengan rentang $\mathrm{pH} 1$ sampai 5 .

Sekitar 1,490 gram potasium klorida dilarutkan dengan akuades dalam tabung volumetrik $100 \mathrm{~mL}$ sampai batas. Kemudian campurkan $5 \mathrm{~mL}$ larutan KCI dengan $67 \mathrm{~mL}$ HCI 0,2 N. Tambahkan HCI kembali jika perlu sampai $\mathrm{pH}$ mencapai $1,0 \pm 0,1$.

Sekitar 1,640 gram potasium asetat dilarutkan dengan akuades dalam tabung volumetrik $100 \mathrm{~mL}$ sampai batas. Tambahkan larutan HCI 0,2 N sampai $\mathrm{pH} 4,5 \pm 0,1$.

\section{Optimasi Konsentrasi}

Kedua ekstrak yang didapat masing-masing dilakukan optimasi konsentrasi (b/v), antara ekstrak dengan larutan menggunakan variasi $0,1 \%, 0,2 \%, 0,3 \%, 0,4 \%$, dan $0,5 \%$ pada 5 tabung reaksi. Dipakai $10 \mathrm{~mL}$ volume larutan uji pada tabung reaksi, dengan massa ekstrak yang disesuaikan pada 5 tabung reaksi. Pencampuran larutan uji dilakukan dengan alat vortex mixer agar mendapatkan larutan yang homogen.

Soeroso et al. (2017) mengemukakan bahwa, antosianin merupakan flavonoid yang memiliki sistem aromatik terkonjugasi, sehingga memiliki dua pita serapan yang berbeda yaitu pada panjang gelombang uv dan sinar tampak. Larutan uji diukur nilai absorbansi pada spektrofotometri UVVis, dengan panjang gelombang $250-700 \mathrm{~nm}$ untuk diambil data optimalnya sebagai acuan dan dilanjutkan pada proses optimasi pH. Data optimal yang diambil adalah data dengan absorbansi <1 untuk mengurangi kesalahan fotometrik.

\section{Optimasi pH}

Kedua ekstrak hasil dari optimasi konsentrasi kemudian dilakukan variasi $\mathrm{pH}$ dari $\mathrm{pH} 1, \mathrm{pH} 2$, $\mathrm{pH} 3, \mathrm{pH} 4$, dan $\mathrm{pH}$ 5. Dipakai 5 tabung reaksi dengan volume larutan uji $10 \mathrm{~mL}$ dengan nilai $\mathrm{pH}$ yang diatur terlebih dahulu. Untuk membuat pengaturan nilai $\mathrm{pH}$, dipakai larutan $\mathrm{pH}$ 1,0 dan 4,5 yang telah dibuat sebelumnya dan dibaca dengan $\mathrm{pH}$ meter digital. Kemudian diukur nilai absorbansi pada spektrofotometri UV-Vis dengan panjang gelombang $250-700 \mathrm{~nm}$, untuk diambil data optimalnya sebagai acuan dan dilanjutkan pada proses optimasi suhu selanjutnya.

\section{Optimasi Suhu}

Kedua ekstrak yang didapat kemudian dilakukan optimasi suhu pada 12 tabung reaksi dengan volume larutan uji $10 \mathrm{~mL}$, yang dipanaskan pada gelas ukur yang berisi air di atas hot plate dengan suhu $30^{\circ} \mathrm{C}, 40^{\circ} \mathrm{C}, 55^{\circ} \mathrm{C}, 70^{\circ} \mathrm{C}$, $85^{\circ} \mathrm{C}$ dan $100^{\circ} \mathrm{C}$ selama 30 menit untuk melihat pengaruhnya pada antosianin.

Kemudian masing-masing ekstrak di analisa dengan menggunakan spektrofotometer UV-Vis dengan panjang gelombang $250-700 \mathrm{~nm}$ untuk dilihat data optimalnya.

\section{HASIL DAN PEMBAHASAN Identifikasi Sampel}

Proses Identifikasi Sampel daun gedi merah (Abelmoschus manihot (L.) Medik) dilakukan di Laboratorium Taksonomi Tumbuhan Program Studi Biologi FMIPA UNSRAT Manado. Identifikasi ini dilakukan untuk membuktikan kebenaran sampel tumbuhan daun gedi merah.

\section{Preparasi Sampel}

Daun gedi merah yang telah dipetik dari Desa Likupang Dua, Kecamatan Likupang Timur, Kabupaten Minahasa Utara lalu disortasi basah. Sortasi dilakukan untuk menghilangkan tanah, kerikil, rumput-rumputan, bagian tanaman lain atau bagian lain dari tanaman yang tidak digunakan dan bagian daun yang rusak. Kemudian 
dicuci untuk menghilangkan kotoran yang menempel pada daun gedi hijau dan dikeringkan di ruangan terbuka dengan panas ruangan selama 1 minggu. Pengeringan dilakukan untuk mengurangi kadar air, mencegah pertumbuhan jamur agar mendapatkan sampel dengan senyawa kimia yang tidak mudah rusak dan dapat disimpan dalam waktu lama.

Sampel yang telah kering, dihaluskan dengan blender kemudian di ayak hingga diperoleh serbuk kering (simplisia). Pembuatan serbuk ini dapat mempermudah proses ekstraksi. Menurut Sapri et al. (2014) ukuran dari serbuk simplisia berpengaruh terhadap rendemen ekstrak yang diperoleh, dimana semakin kecil ukuran serbuk simplisia, maka semakin besar rendemen ekstrak. Hal tersebut dikarenakan semakin kecil ukuran serbuk maka permukaan dari serbuk semakin luas sehingga memperbesar terjadinya kontak antar partikel serbuk dengan pelarut.

\section{Hasil Ekstraksi}

Dalam proses ekstraksi, pemilihan pelarut memegang peranan penting untuk menentukan berhasil atau tidaknya proses ekstraksi tersebut. Jenis-jenis solven yang sering digunakan dalam mengekstrak suatu bahan produk antara lain : asam asetat, metanol, etanol, dan air (Angelia, 2019).

Menurut Sampebarra (2018) umumnya cara mengekstrak antosianin menggunakan pelarut dan asam, dimana fungsi pelarut merupakan faktor yang menentukan kualitas dari antosianin sedangkan penambahan asam berfungsi untuk lebih mengoptimalkan ekstraksi antosianin. Oleh karena itu peneliti menggunakan $\mathrm{HCl}$ dan Asam Sitrat sebagai pengasam dalam proses ekstraksi.

Penurunan $\mathrm{pH}$ ekstraksi dapat dilakukan dengan menambahkan senyawa asam, salah satu senyawa asam yang dapat digunakan adalah asam sitrat. Asam sitrat diproduksi dalam bentuk kristal dan memiliki kriteria yang tidak berwarna, berasa asam, tidak berbau dan lebih cepat larut dalam air panas (Surianti et al., 2012).

Santoni et al. (2013) mengemukakan bahwa pengasaman dengan asam lemah menghindari hidrolisis dari antosianin dibandingkan dengan asam kuat $\mathrm{HCl}$. Hal tersebut menjadikan acuan asam sitrat dipilih sebagai asam lemah agar dapat melihat perbedaannya dengan asam kuat $\mathrm{HCl}$ pada proses analisis antosianin.

Setiap sampel sebanyak 100 gram serbuk simplisia daun gedi merah dimasukkan ke dalam wadah toples kaca dan di tambahkan metanol
$1000 \mathrm{~mL}$. Ekstraksi dilakukan dengan cara maserasi selama 24 jam, kemudian disaring dan didapatkan filtrat. Filtrat yang diperoleh kemudian dimasukkan ke dalam oven dengan suhu maksimal $40^{\circ} \mathrm{C}$ agar tidak merusak senyawa yang terkandung dalam ekstrak, hingga diperoleh ekstrak kental.

Berdasarkan hasil ekstraksi 100 gram daun gedi merah maka diperoleh jumlah hasil rendemen dari masing-masing ekstrak adalah Metanol + $0,1 \% \mathrm{HCl}$ sebesar $18,45 \%$ dan Metanol $+3 \%$ Asam Sitrat sebesar 23,56\%. Hal ini dikarenakan Asam Sitrat merupakan asam lemah jika dibandingkan dengan $\mathrm{HCl}$. Menurut Santoni et al. (2013) dan Surianti et al. (2012) penggunaan Asam Sitrat dapat menghasilkan ekstrak antosianin yang lebih banyak dibandingkan dengan $\mathrm{HCl}$. Hal ini karena $\mathrm{HCl}$ yang meskipun merupakan asam kuat, masih tetap beresiko untuk menghidrolisis ikatan glikosidik antosianin yang dapat mengakibatkan ketidakstabilan pada antosianin, sedangkan Asam Sitrat adalah asam lemah yang bersifat sama dengan antosianin yaitu sama-sama bersifat polar sehingga lebih mudah mengekstrak antosianin.

\section{Optimasi Konsentrasi}

Dari hasil pengukuran spektrum yang didapat, diambil konsentrasi $0,1 \%$ (b/v) untuk kedua ekstrak $\mathrm{HCl}$ dan Asam Sitrat sebagai hasil optimum untuk analisis selanjutnya pada variasi pH. Pada tabel 1 dan 2 dapat dilihat pada konsentrasi $0,1 \%$ tersebut dari kedua ekstrak memiliki nilai absorbansi kecil dari 1 yang bertujuan untuk meminimalisir kesalahan fotometrik pada pengukuran dan masih pada kisaran absorbansi $0,2-0,8$ yang tergolong stabil.

Tabel 1. Optimasi Konsentrasi $\mathrm{HCl}$

\begin{tabular}{ccc}
\hline \hline Konsentrasi & Abs & Panjang Gelombang \\
\hline $0,1 \%$ & 0,455 & 535,5 \\
$0,2 \%$ & 0,682 & 535,5 \\
$0,3 \%$ & 1,078 & 535,5 \\
$0,4 \%$ & 1,727 & 535,5 \\
$0,5 \%$ & 1,784 & 535,5 \\
\hline
\end{tabular}

Tabel 2. Optimasi Konsentrasi Asam Sitrat

\begin{tabular}{ccc}
\hline \hline Konsentrasi & Abs & Panjang Gelombang \\
\hline 0,1 & 0,230 & 535 \\
0,2 & 0,379 & 535 \\
0,3 & 0,540 & 535 \\
0,4 & 0,641 & 535 \\
0,5 & 0,774 & 535 \\
\hline
\end{tabular}


Optimasi konsentrasi dari $0,1 \%, 0,2 \%, 0,3 \%$, $0,4 \%$, dan $0,5 \%$ (b/v) untuk kedua ekstrak tersebut, dilakukan dengan menambahkan ekstrak metanol $+\mathrm{HCl}$ dan metanol + Asam Sitrat ke dalam pelarut dengan 5 variasi yang berbeda dalam 5 tabung reaksi. Menurut Santoni et al. (2013) konsentrasi mempengaruhi intensitas warna dari larutan, intensitas warna larutan

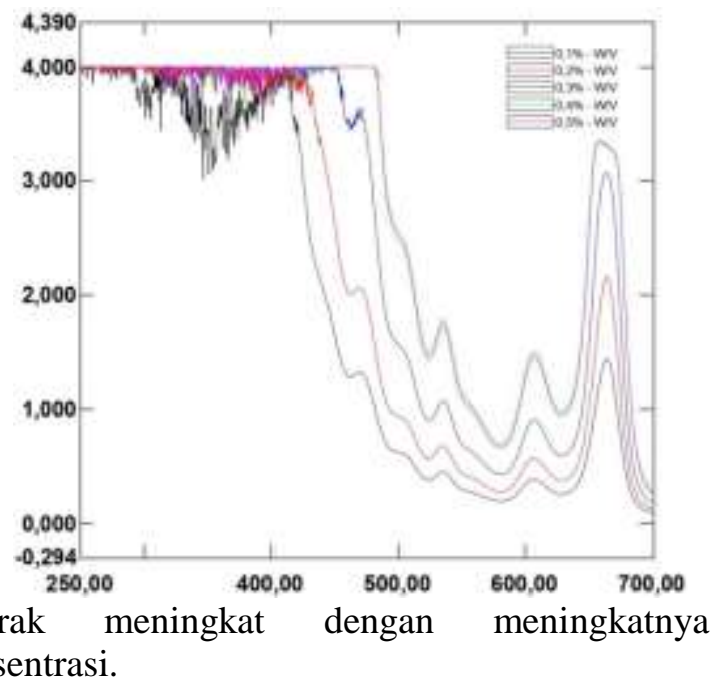

Gambar 1. Spektrum konsentrasi ekstrak $\mathrm{HCl}$

\section{Optimasi pH}

Spektrum optimasi $\mathrm{pH}$ dapat dilihat pada gambar 3 dan 4. Karakteristik senyawa antosianin yaitu mempunyai daerah serapan pada panjang gelombang visibel 490 - 550nm (Santoni et al., 2013). Perubahan warna ekstrak antosianin tanaman gedi merah terhadap pengaruh $\mathrm{pH}$ merupakan suatu indikator dari antosianin tersebut

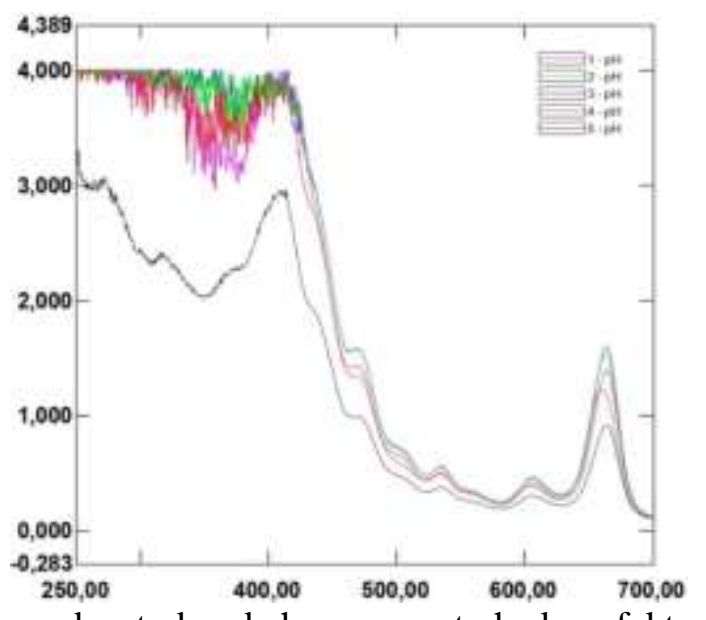

karena dapat berubah warna terhadap faktor keasaman dan kebasaan. Warna pada larutan uji

Gambar 3. Spektrum $\mathrm{pH}$ ekstrak $\mathrm{HCl}$
Pada penelitian yang dilakukan Santoni et al. (2013) spektrum yang didapat menunjukkan semakin besar konsentrasi maka absorbansi dari larutan juga semakin besar. Hal ini mendukung hasil absorbansi yang didapat pada tabel 1 dan 2 serta spektrum pada gambar 1 dan 2, dimana konsentrasi yang makin ditingkatkan

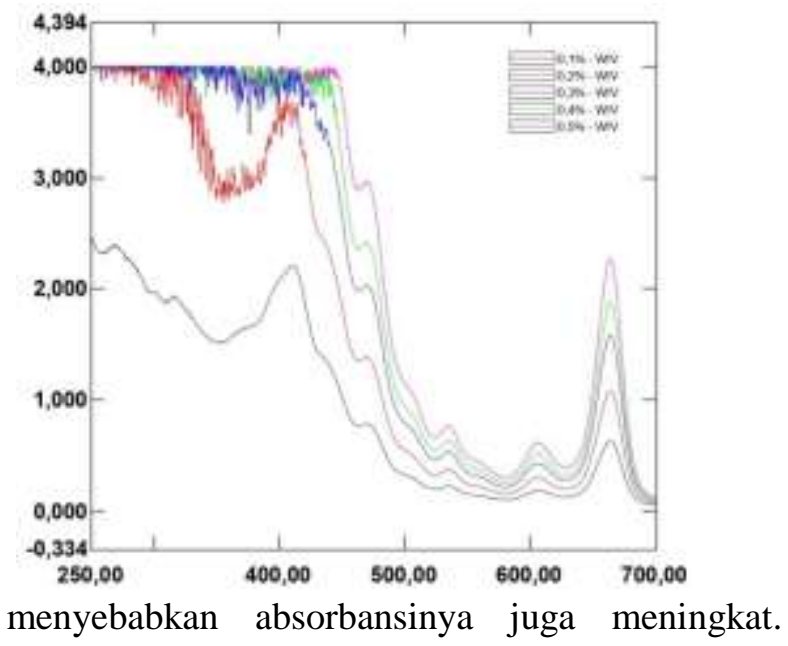

Gambar 2. Spektrum konsentrasi ekstrak Asam Sitrat

esktrak daun gedi merah yang dihasilkan adalah hijau kekuningan dengan saturasi warna yang semakin berkurang seiring dinaikkannya $\mathrm{pH}$ larutan uji. Hal ini sesuai dengan penelitian sebelumnya yang dilakukan oleh Pratiwi dan Priyani (2019) yang menyatakan pada pH 1 antosianin berbentuk kation flavilium yang berwarna, sedangkan pada $\mathrm{pH} 4,5$ antosianin

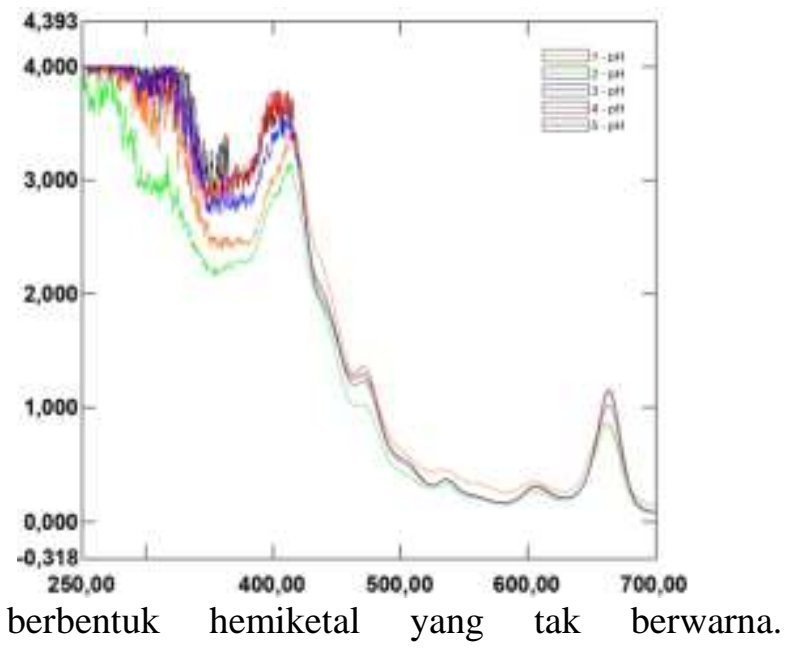

Gambar 4. Spektrum pH ekstrak Asam Sitrat 
Dapat dilihat pada tabel 3 dan 4 hasil pengukuran absorbansi variasi $\mathrm{pH}$ antosianin daun gedi merah memiliki nilai absorbansi rata-rata 0,3 untuk asam sitrat dan 0,5 untuk $\mathrm{HCl}$. Penelitian sebelumnya yang dilakukan oleh Inggrid dan Iskandar (2016) pada variasi terendah $\mathrm{pH} 2$ menghasilkan kadar antosianin yang paling besar dan hasil terendah kadar antosianin pada variasi tertinggi $\mathrm{pH}$ 12. Berdasarkan hal itu penulis memilih variasi terendah yaitu $\mathrm{pH} 1$ sebagai hasil optimum untuk dilanjutkan pada proses variasi suhu selanjutnya.

Tabel 3. Optimasi $\mathrm{pH} \mathrm{HCl}$

\begin{tabular}{ccc}
\hline \hline $\mathbf{p H}$ & Abs & Panjang Gelombang \\
\hline 1 & 0,491 & 534,5 \\
2 & 0,551 & 535 \\
3 & 0,560 & 535 \\
4 & 0,507 & 535 \\
5 & 0,376 & 535,5 \\
\hline
\end{tabular}

Tabel 4. Optimasi pH Asam Sitrat

\begin{tabular}{ccc}
\hline $\mathbf{p H}$ & Abs & Panjang Gelombang \\
\hline 1 & 0,458 & 534,5 \\
2 & 0,326 & 535,5 \\
3 & 0,368 & 536 \\
4 & 0,374 & 536 \\
5 & 0,375 & 536 \\
\hline
\end{tabular}

\section{Optimasi Suhu}

Ekstrak antosianin daun gedi merah dioptimasi pada variasi suhu $30^{\circ} \mathrm{C}, 40^{\circ} \mathrm{C}, 55^{\circ} \mathrm{C}$, $70^{\circ} \mathrm{C}, 85^{\circ} \mathrm{C}$, dan $100^{\circ} \mathrm{C}$. Pemanasan dilakukan selama 30 menit pada larutan uji dalam tabung reaksi yang dipanaskan dalam gelas ukur berisi air di atas hotplate.

Menurut Sampebarra (2018), pada temperatur yang tinggi antosianin mengalami dekomposisi/perubahan struktur sehingga sangat mudah terdegradasi. Pada gambar 5 dapat dilihat perubahan yang tidak signifikan pada warna larutan uji yang semakin pudar seiring dinaikkannya suhu pada hotplate.

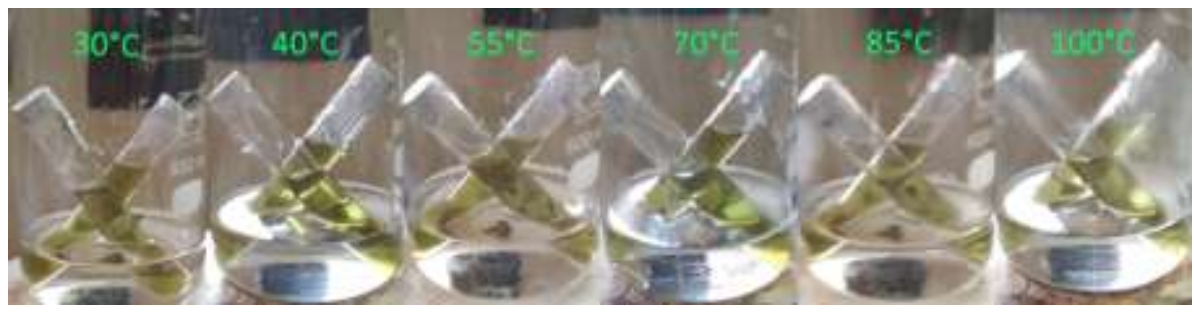

Gambar 5. Degradasi Warna Antosianin Daun Gedi Merah

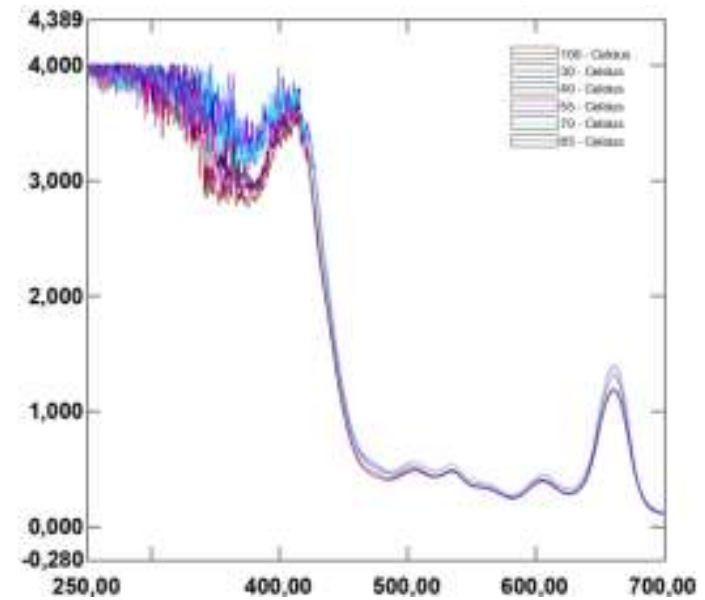

Gambar 6. Spektrum suhu ekstrak $\mathrm{HCl}$

Perubahan warna yang tidak signifikan larutan uji pada gambar 5, serta spektrum optimasi suhu pada gambar 6 dan 7 berkaitan dengan hasil absorbansi yang didapat. Pada gambar tersebut bisa dilihat meski setelah dipanaskan, warna

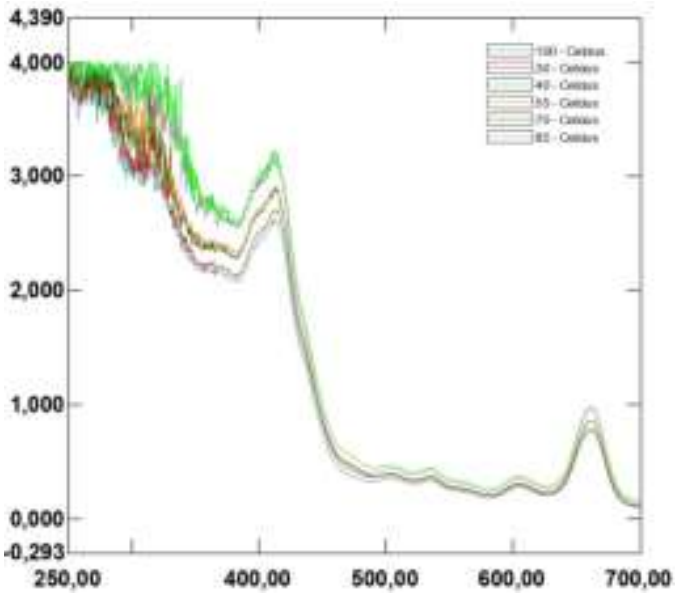

Gambar 7. Spektrum suhu ekstrak Asam Sitrat

larutan uji masih sangat tampak yang menandakan antosianin didalamnya masih belum terdegradasi sempurna, serta spektrum yang dihasilkan tidak jauh berbeda pada setiap variablel suhu yang diberikan. 
Pada tabel 5 dan 6 dapat dilihat rata-rata nilai absorbansi yang dihasilkan untuk $\mathrm{HCl} 0,5$ dan Asam Sitrat 0,3 yang menandakan antosianin masih dalam keadaan stabil. Hasil yang didapatkan dibedakan dengan penelitian sebelumnya oleh Santoni et al. (2013) dimana berkurangnya intensitas warna terhadap kenaikan suhu pemanasan didukung dengan semakin menurunnya absorbansi pada daerah serapan visibel, hal ini menandakan rusak antosianin terhadap suhu pemanasan. Berdasarkan hal tersebut, optimasi suhu antosianin daun gedi merah tergolong stabil meski telah dilakukan pemanasan.

Tabel 5. Optimasi Suhu $\mathrm{HCl}$

\begin{tabular}{ccc}
\hline Suhu & Abs & Panjang Gelombang \\
\hline $30^{\circ} \mathrm{C}$ & 0,357 & 535 \\
$40^{\circ} \mathrm{C}$ & 0,446 & 535 \\
$55^{\circ} \mathrm{C}$ & 0,374 & 535 \\
$70^{\circ} \mathrm{C}$ & 0,377 & 535 \\
$85^{\circ} \mathrm{C}$ & 0,424 & 535 \\
$100^{\circ} \mathrm{C}$ & 0,336 & 535 \\
\hline
\end{tabular}

Tabel 6. Optimasi Suhu Asam Sitrat

\begin{tabular}{ccc}
\hline Suhu & Abs & Panjang Gelombang \\
\hline $30^{\circ} \mathrm{C}$ & 0,479 & 534,5 \\
$40^{\circ} \mathrm{C}$ & 0,502 & 534,5 \\
$55^{\circ} \mathrm{C}$ & 0,544 & 534,5 \\
$70^{\circ} \mathrm{C}$ & 0,543 & 534,5 \\
$85^{\circ} \mathrm{C}$ & 0,493 & 534,5 \\
$100^{\circ} \mathrm{C}$ & 0,481 & 534,5 \\
\hline
\end{tabular}

\section{KESIMPULAN}

Menurut hasil penelitian, total rendemen ekstrak $\mathrm{HCl}$ yang didapat sebesar $18,45 \%$ dan Asam Sitrat sebesar 23,56\%. Optimasi senyawa antosianin daun gedi merah mendapatkan hasil optimumnya pada konsentrasi $0,1 \%$ (b/v), pH 1 dan semua variabel suhu yang diterapkan masih menunjukkan antosianin yang stabil dengan ratarata absorbansi pada ekstrak $\mathrm{HCl} 0,4$ dan Asam Sitrat 0,3 .

\section{SARAN}

Perlu dilakukan penelitian lebih lanjut terhadap optimasi konsentrasi, $\mathrm{pH}$ dan suhu antosianin Daun Gedi Merah (Abelmoschus manihot (L.) Medik.), dengan memakai variabel yang lebih luas agar dapat terlihat perbedaan yang signifikan pada hasil uji, serta penggunaan pengasam yang berbeda pada proses ekstraksi untuk melihat pengaruhnya terhadap proses ekstraksi antosianin daun gedi merah.

\section{DAFTAR PUSTAKA}

Angelia, I. O. 2019. Variasi Konsentrasi Solven Pada Proses Ekstraksi Antosianin Dari Ubi Jalar Ungu. Journal of Agritech Science. 3: 16-26.

Banne, Y., T. S. Ponidjan., J.M. Dumanauw. 2019. Antioxidant And Hepatoprotective Activity Of Abelmoschus manihot L. Medik Leaf Fraction Against CCl4-Induced Liver Damage In Rats. International Journal of Applied Pharmaceutics. 11: 17-19.

Inggrid, H. Maria., dan A. R. Iskandar. 2016. Pengaruh $\mathrm{pH}$ dan Temperatur pada Ekstraksi Antioksidan dan Zat Warna Buah Stroberi. Di dalam: Pengembangan Teknologi Kimia untuk Pengolahan Sumber Daya Alam Indonesia. Prosiding Seminar Nasional Teknik Kimia "Kejuangan"; Yogyakarta, 17 Maret 2016. Program Studi Teknik Kimia, FTI, UPN "Veteran" Yogyakarta.

Julianto, S. T. 2019. Fitokimia Tinjauan Metabolit Sekunder dan Skrining Fitokimia. Universitas Islam Indonesia, Yogyakarta.

Pratiwi, S. W \& A. A. Priyani. 2019. Pengaruh Pelarut Dalam Berbagai Ph Pada Penentuan Kadar Total Antosianin Dari Ubi Jalar Ungu Dengan Metode pH Diferensial Spektrofotometri. Jurnal Kimia dan Pendidikan. 4: 89-96.

Priska, M., N. Peni., L. Carvallo \& Y. D. Ngapa. 2018. Review: Antosianin Dan Pemanfaatannya. Cakra Kimia. 6: 79-97.

Sampebarra, A. L. 2018. Karakteristik Zat Warna Antosianin Dari Biji Kakao Non Fermentasi Sebagai Sumber Zat Warna Alam. Jurnal Industri Hasil Perkebunan. 13: 63-70.

Santoni, A., D. Darwias., S. Syahri. 2013. Isolasi Antosianin dari Buah Pucuk Merah (syzygium campanulatum korth.) Serta Pengujian Antioksidan dan Aplikasi sebagai Pewarna Alami. Prosiding Seminar dan Rapat Tahunan Bidang MIPA BKS 
PTN Wilayah Barat; Lampung, 10-12 Mei 2013.

Sapri., A. Fitriana., R. Narulita. 2014. Pengaruh Ukuran Serbuk Simplisia Terhadap Rendemen Ekstrak Etanol Daun Sirsak (Annona muricata L.) dengan Metode Maserasi. Di dalam: Seminar Nasional Kimia 2014. Prosiding Seminar Kimia.

Soeroso, E. G., L. N. Lestario \& Y. Martono. 2017. Penambahan Gula dapat Meningkatkan Stabilitas Warna Ekstrak Antosianin Buah Murbei Hitam yang Terpapar Cahaya Fluoresens. Jurnal Teknologi dan Industri Pangan. 28: 62-69.

Surianti, N.A., I. G. N. Agung \& G. D. Puspawati. 2012. Pengaruh Konsentrasi Asam Sitrat Terhadap Karakteristik Ekstrak Pigmen Limbah Selaput Lendir Biji Terung Belanda (Cyphomandra beatacea S.) dan Aktivitas Antioksidannya. Jurnal Ilmu dan Teknologi Pangan. 1: 1-10.

Yusuf, M., S. Indriati \& N. F. U. Attahmid. 2018. Karakterisasi Antosianin Kubis Merah Sebagai Indikator Pada Kemasan Cerdas. Jurnal Galung Topika. 7: 46-5 